\title{
Enhanced Nitrogen and Phosphorus Removal by Natural Pyrite based Constructed Wetland with Intermittent Aeration
}

\section{Liya Li}

Hefei University of Technology

Jingwei Feng ( $\nabla_{\text {jingweifeng@hfut.edu.cn ) }}$

Hefei University of Technology https://orcid.org/0000-0002-0486-6675

Liu Zhang

Anhui Academy of Environmental Science and Research

Hao Yin

University of Science and Technology of China

\section{Chunli Fan}

Hefei University of Technology

\section{Zechun Wang}

Hefei University of Technology

\section{Menglei Zhao}

Hefei University of Technology

Chengchang Ge

Hefei University of Technology

Hao Song

Hefei University of Technology

\section{Research Article}

Keywords: Constructed wetlands, Intermittent aeration, Autotrophic denitrification, Enzyme activity, Microbial community structure, Canonical correspondence analysis

Posted Date: April 19th, 2021

DOl: https://doi.org/10.21203/rs.3.rs-389894/v1

License: (c) (1) This work is licensed under a Creative Commons Attribution 4.0 International License.

Read Full License 
Version of Record: A version of this preprint was published at Environmental Science and Pollution Research on July 20th, 2021. See the published version at https://doi.org/10.1007/s11356-021-15461-6. 
1 Enhanced nitrogen and phosphorus removal by natural pyrite based

$21 *$ Corresponding authors. E-mail address: jingweifeng@hfut.edu.cn (JW Feng), zlbod5@163.com

(L Zhang) Tel./Fax: $+86-551-62904144$ (JW +86-551-63545151 (L Zhang)

\section{constructed wetland with intermittent aeration}

1 Anhui Provincial Engineering Laboratory for Rural Water Environment and Resources, School of Civil and Hydraulic Engineering, Hefei University of Technology, Hefei 230009, China

2 State Key Laboratory of Pollution Control \& Resources Reuse, School of the Environment, Nanjing University, Nanjing 210046, China

3 Anhui Province Key Laboratory of Industrial Wastewater and Environmental Treatment, Hefei 230024, China

4 Anhui Academy of Environmental Science and Research, Hefei 230001, China

5 CAS Key Laboratory of Crust-Mantle Materials and the Environments, School of Earth and Space Sciences, University of Science and Technology of China, Hefei 230026,

\section{China}

6 Mass Spectrometry Lab, Hefei National Laboratory for Physical Sciences at Microscale, University of Science and Technology of China, Hefei 230026, China. 
25 Abstract: Four subsurface flow constructed wetlands (SFCWs) filled with different substrates including ceramsite, ceramsite+pyrite, ceramsite+ferrous sulfide, and ceramsite+pyrite+ferrous sulfide (labeled as SFCW-S1, SFCW-S2, SFCW-S3, and SFCW-S4) were constructed, and the removal of nitrogen and phosphorus by these SFCWs coupled with intermittent aeration in the front section was discussed. The key findings from different substrate analyses, including nitrification and denitrification rate, enzyme activity, microbial community structure, and the X-ray diffraction, revealed the nitrogen and phosphorus removal mechanism. The results showed that the nitrogen and phosphorus removal efficiency for SFCW-S1 always remains the lowest, and the phosphorus removal efficiency for SFCW-S4 is recorded as the highest one. However, after controlling the dissolved oxygen by intermittent aeration in the front section of SFCWs, the nitrogen and phosphorus removal efficiencies of SFCWs-S2 and S4 becomes higher than those of SFCW-S1, and SFCW-S3. It was noticed that the pollutants were removed mainly in the front section of the SFCWs. Both precipitation and adsorption on the substrate were the main mechanisms for phosphorus removal. A minute difference of nitrification rate and ammonia monooxygenase activity was observed in the SFCWs aeration zone. The denitrification rates, nitrate reductase, nitrite reductase, and electron transport system activity for SFCW-S2 and SFCW-S4 were higher than those detected for SFCW-S1 and SFCW-S3 in the non-aerated zone. Proteobacteria was the largest phyla found in the SFCWs. Moreover, Thiobacillus occupied a large proportion found in SFCW-S2, and SFCW-S4, and it played a crucial role in pyrite-driven autotrophic denitrification.

Keywords: Constructed wetlands; Intermittent aeration; Autotrophic denitrification; Enzyme activity; Microbial community structure; Canonical correspondence analysis 
Introduction

Urban inland rivers in China are mostly seasonal rivers, the water quality of these

51 rivers is often affected by the sewage treatment plants effluent intrusion and rainstorm runoff mixing. As a result, these seasonal rivers gradually form black and smelly water bodies, called low pollution water, which is a great threat to ecological environment sustainability and human water safety concerns. In recent years, the purification of low pollution water polluted by the sewage treatment plants effluent intrusion and storm runoff mixing has attracted extensive attention for researchers.

Constructed wetlands (CWs) are widely utilized for advanced wastewater treatment purpose due to their relatively low cost, low energy demand feasibility, ease of operation, and beautification effect (Abou-Kandil et al. 2021, Baldovi et al. 2021, Rizzo et al. 2020). Heterotrophic denitrification is the main denitrification mechanism in traditionally CWs, and carbon source is considered the main limiting factor for the denitrification process (Pan et al. 2020, Si et al. 2018, Tan et al. 2020, Wang et al. 2021). Theoretically, the estimated $\mathrm{C} / \mathrm{N}$ ratio for heterotrophic denitrification is 3.74 (Anjali \&Sabumon 2015, Chiu \&Chung 2003). In the case of application of the CWs for low pollution water purification, the $\mathrm{C} / \mathrm{N}$ ratio for most low pollution water is lower than the value reported above, which makes it challenging to meet the carbon source requirements of heterotrophic denitrification process. Thus results in limited biological denitrification process as well as poor in term of denitrification efficiency. To boost the denitrification process, carbon sources can be added to improve denitrification efficiency. Generally, it is suggested that the higher carbon content availability in the influent is conducive to

71 converting nitrate or nitrite into nitrogen, which produces less $\mathrm{N}_{2} \mathrm{O}$. However, excessive organic carbon availability in the influent will lead to the increase of unused carbon 
sources in the denitrification process, in which become a cause of secondary pollution spreading, reactor blockage, and high effluent turbidity.

Moreover, in case of autotrophic denitrification, denitrifying bacteria reduce $\mathrm{NO}_{3}{ }^{-}-\mathrm{N}$ to $\mathrm{N}_{2}$ by using $\mathrm{H}_{2}$, sulfide, sulfur, and reductive iron as electron donors, and $\mathrm{NO}_{3}{ }^{-}$as electron acceptor. The compounds including $\mathrm{CO}_{2}, \mathrm{HCO}_{3}{ }^{-}, \mathrm{CO}_{3}{ }^{2-}$ are used as inorganic carbon sources. The sludge yield in the autotrophic denitrification process remains comparatively low, and no additional organic carbon source is needed to accomplish the task, which can effectively remove $\mathrm{NO}_{3}^{-}-\mathrm{N}$ from low $\mathrm{C} / \mathrm{N}$ sewage. Previous studies have shown that elemental sulfur's autotrophic denitrification process will lead to a drop in solution $\mathrm{pH}$ and produce a large amount of sulfate (Li et al. 2020, Sahinkaya et al. 2011, Wang et al. 2020). Therefore, pyrite is considered a good choice for autotrophic denitrification, low cost, stable $\mathrm{pH}$, and less sulfate formation. The production of sulfate in the process of $\mathrm{FeS}$ autotrophic denitrification also remains much lower, when compared with elemental sulfur autotrophic denitrification.

In the present study, subsurface flow constructed wetlands (SFCWs) with different substrates ceramsite (SFCW-S1), ceramsite+pyrite (SFCW-S2), ceramsite+ferrous sulfide (SFCW-S3), and ceramsite+pyrite+ferrous sulfide (SFCW-S4) were used for the purification of low pollution water, i.e., seasonal river water contaminated by the sewage treatment plant effluent and storm runoff. The main research objectives for this study were as follows: (1) comparing the purification efficiency of CWs filled with different substrates with and without intermittent aeration; (2) exploring the nitrogen and phosphorus removal effects of CWs filled with different substrates, as well as the nitrogen removal effects of ferrous sulfide and pyrite as electron donors; (3) analyzing the migration and transformation of nitrogen elements, microbial activity, and community structure in CWs, as well as the nitrogen and phosphorus removal mechanism. 


\section{Materials and methods}

\section{Chemical Reagents}

Sulphuric acid, methanol, anhydrous sodium acetate, sodium nitrate, and potassium dihydrogen phosphate (Analytical Reagent) were all purchased from Sinopharm Chemical Reagents Co., Ltd, Shanghai, China. NADH (100\%) is obtained from Sigma-Aldrich, Germany. Formaldehyde solution, phenol, potassium chloride, sodium chloride, sodium disulfite, sodium nitrite, ammonium sulfate, anhydrous sodium dihydrogen phosphate, D-anhydrous glucose, disodium hydrogen phosphate, potassium chloride, iodonitrotetrazolium chloride (INT, 98\%), and N-allyl thiourea (Analytical Reagent) were produced by Shanghai Macklin Biochemical Co., Ltd, China.

\section{Experimental apparatus and methods}

Total four SFCWs labeled as SFCW-S1, SFCW-S2, SFCW-S3, and SFCW-S4 were constructed having same dimensions (length $\times$ width $\times$ height $=80 \mathrm{~cm} \times 30 \mathrm{~cm} \times 60 \mathrm{~cm}$ ). The experimental apparatus diagram has been presented in Fig.1. Moreover, the filling structure of substrates has given in Table 1. Three cannas plants were planted at equal intervals in total of four SFCWs. The aeration pipe was located in the first chamber of the four SFCWs. The total aeration time was $20 \mathrm{~h}$ per day, 8 cycles per day. The experiment was carried out from September 1, 2020 to January 16, 2021. A certain amount of compounds $\mathrm{CH}_{3} \mathrm{COONa}, \mathrm{NH}_{4} \mathrm{Cl}, \mathrm{KNO}_{3}$, and $\mathrm{KH}_{2} \mathrm{PO}_{4}$ was dissolved in the tap water to prepare the synthetic wastewater. The influent water quality of the four SFCWs has been given in Table $\mathrm{S} 1$.

\section{Analysis methods}

The conventional water quality index was analyzed by adopting standard methods (Table S2). Biofilm denitrification rate (DNR) of the CWs substrates is calculated by the 
$141 \quad \frac{A B S_{490}}{15.9} \frac{V_{1}}{V_{0} t} \frac{32}{2} \frac{1}{m}$ (Yang et al. 2020).

where $A$ is the amount of removed nitrate during the reaction (mg), $T$ is the reaction time (h), and $B$ is the amount of biomass used during the reaction $(\mathrm{g})$.

The biofilm nitrification rate of the CWs substrates has represented by ammonium oxidation rate (AOR). AOR was calculated by the decrease in $\mathrm{NH}_{4}{ }^{+}-\mathrm{N}$ concentration over time and divided by the initial biomass (Eq. (2)) (Zhang et al. 2017):

$$
\mathrm{AOR}=\mathrm{C} /(\mathrm{T} \times \mathrm{B})
$$

where $C$ is the amount of $\mathrm{NH}_{4}{ }^{+}-\mathrm{N}$ removed during the reaction $(\mathrm{mg}), T$ is the reaction time $(\mathrm{h})$, and B is the amount of biomass used during the reaction $(\mathrm{g})$.

The determination methods of ammonia monooxygenase (AMO), nitrite reductase (NIR), and nitrate reductase (NAR) activities has been described in the previous study

The electron transport system activity (ETSA) of the bacteria was determined by reducing 2-(p-iodophenyl)-3-(p-nitrophenyl)-5-phenyl tetrazolium chloride (INT, a kind of exogenous electron acceptor) to formazan (INF). ETSA was calculated according to the following formula (Eq. (3)) (Yang et al. 2020):

142 where $A B S_{490}$ is the sample absorbance, 15.9 is the specific absorptivity of INT-formazan, $143 V_{0}$ and $V_{l}$ are the initial volume of bacteria and the total volume of methanol (mL), $t$ is the 144 incubation time ( $\mathrm{min}$ ), $32 / 2$ is the constant for the transformation of $\mu$ mol INT-formazan 145 to $\mu \mathrm{g} \mathrm{O}_{2}$, and $m$ is the protein concentration per milliliter of bacteria (mg protein $/ \mathrm{mL}$ 146 bacteria). 
X-ray diffraction (XRD) characterization of substrates was performed by the X-ray diffractometer (X'Pert Pro MPD, PANalytical, Netherlands).

Microbial community structure was determined by Sangon Biotech (Shanghai) Co., Ltd., China. The selected amplification area was 16S RNA V3-V4. The main process of metagenome sequencing was: sample DNA extraction, library construction and sequencing. DNA was extracted by DNA kit, and then the target sequences were enriched by highly specific primers. Finally, the sequencing data were analyzed by bioinformatics.

\section{Results and discussion}

\section{Effects of SFCWs substrates on the removal of pollutants}

The overall performance of SFCWs series for the removal of COD $\mathrm{Cr}$ was monitored. The removal of $\mathrm{COD}_{\mathrm{Cr}}$ by SFCWs having different substrates has presented in Fig. S1. As-obtained results from one-way ANOVA showed that there was no significant difference found for $\mathrm{COD}_{\mathrm{Cr}}$ removal efficiency for all SFCWs before and after aeration $(p>0.05)$. This endorsed that the substrates and aeration have little effect on the $\mathrm{COD}_{\mathrm{Cr}}$ removal by SFCWs series.

Furthermore, as depicted in Fig. 2a, the effluent concentration of total nitrogen (TN) fluctuated between 1.44 and $10.18 \mathrm{mg} / \mathrm{L}$. During initial stage in SFCWs, the adsorption and ion exchange of substrates were responsible for the removal of $\mathrm{TN}$ and $\mathrm{NH}_{4}{ }^{+}-\mathrm{N}$ (Buelna et al. 2008, Yuan et al. 2020), which supported that the initial removal efficiency of TN and $\mathrm{NH}_{4}{ }^{+}-\mathrm{N}$ was relatively higher (Fig. 2b and Fig. 2d). As the absorption of $\mathrm{NH}_{4}{ }^{+}-\mathrm{N}$ by the substrate tends to be saturated, the abundance of ammonia-oxidizing bacteria in the system is not enough to oxidize $\mathrm{NH}_{4}{ }^{+}-\mathrm{N}$, and the removal efficiency of $\mathrm{NH}_{4}{ }^{+}-\mathrm{N}$ begins to decline. As both $\mathrm{COD}_{\mathrm{Cr}}$ and microorganism of SFCWs compete for dissolved oxygen (DO), so DO level in the wetland got decrease, then the conversion rate of $\mathrm{NH}_{4}{ }^{+}-\mathrm{N}$ was slowed down and the removal efficiency of TN was reduced ( $\mathrm{Li}$ et al. 
2017, Sun et al. 2004). For 30-65 days, the influent concentration of TN was ranged from $17.56-22.86 \mathrm{mg} / \mathrm{L}$, the influent load increased from range $0.32-0.39 \mathrm{~g} / \mathrm{d}$ to $0.49-0.60 \mathrm{~g} / \mathrm{d}$. Both SFCW -S2 and S4 exhibited a relatively higher TN removal efficiency (35.74\%-71.79), while SFCW-S1 and SFCW-S3 have shown comparatively low TN removal efficiency. In addition, SFCW-S1 has reflected a consistently low TN removal efficiency even before and after aeration.

Before aeration, the DO level in the wetland was $0-0.7 \mathrm{mg} / \mathrm{L}$ (Fig. S2), and the $\mathrm{NH}_{4}{ }^{+}-\mathrm{N}$ average removal efficiencies for SFCW-S1, SFCW-S2, SFCW-S3, and SFCW-S4 were $71.58 \%, 77.58 \%, 58.74 \%$, and $48.36 \%$, respectively, which suggested the moderate nitrification capacity at low DO level (Anjali \&Sabumon 2015, Bernat et al. 2011). After 30-65 days, aeration was done to reduce the accumulated $\mathrm{NH}_{4}{ }^{+}-\mathrm{N}$ in the wetland. After aeration, DO levels in the wetland increased dramatically (Fig. S2), which is favorable for the growth and metabolism of aerobic organisms (Yuan et al. 2020). The $\mathrm{NH}_{4}{ }^{+}-\mathrm{N}$ concentration in effluent of the four SFCWs decreased significantly after aeration, which met the Class III standard of the Environmental Quality Standard for Surface Water (EQSSW) (GB 3838-2002, China), and the removal efficiency of $\mathrm{NH}_{4}{ }^{+}-\mathrm{N}$ was basically above $90 \%$. In addition to aeration, the reason for the high $\mathrm{NH}_{4}{ }^{+}-\mathrm{N}$ removal efficiency during the later stage might be the good growth of plants, which released a large amount of oxygen as electron acceptor to promote the oxidation of $\mathrm{NH}_{4}{ }^{+}-\mathrm{N}$ (Yuan et al. 2020).

Furthermore, there was no production of $\mathrm{NO}_{3}^{-}-\mathrm{N}$ detected in SFCW-S4 and SFCW-S3 during the period 0-30 days before aeration as reflected in Fig. 2e, and the denitrification rate was the highest. While the concentration of $\mathrm{NO}_{3}^{-}-\mathrm{N}$ in $\mathrm{S} 1$ effluent was 3.30-5.28 $\mathrm{mg} / \mathrm{L}$, and the denitrification rate was relatively the lowest. After the aeration of the wetland, the increase in DO level led to conversion of $\mathrm{NH}_{4}{ }^{+}-\mathrm{N}$ to $\mathrm{NO}_{3}{ }^{-} \mathrm{N}$, and the 
concentration of $\mathrm{NO}_{3}{ }^{-}-\mathrm{N}$ in the effluent of the four SFCWs got increased. The $\mathrm{NO}_{3}{ }^{-}-\mathrm{N}$ can be removed by denitrification, partial denitrification, and anammox in constructed wetland. Because of the low carbon-nitrogen ratio in the influent, the $\mathrm{NO}_{3}{ }^{-} \mathrm{N}$ concentration in wetland SFCW-S1 was higher due to lack of denitrification carbon source, while $\mathrm{NO}_{3}{ }^{-} \mathrm{N}$ concentration in wetland SFCW-S2, SFCW-S3, and SFCW-S4 was lower, indicating that pyrite and ferrous sulfide in SFCW-S2, SFCW-S3, and SFCW-S4 play an essential role in the removal of $\mathrm{NO}_{3}{ }^{-}-\mathrm{N}$.

It was noticed that the effluent $\mathrm{NO}_{2}^{-}-\mathrm{N}$ concentration in the four SFCWs increased first and then gradually decreased as demonstrated in Fig. 2f. By comparing the overall four SFCWs, it was found that the effluent $\mathrm{NO}_{2}^{-}-\mathrm{N}$ concentration in SFCW-S3 and SFCW-S4 was the highest among others. The accumulation of $\mathrm{NO}_{2}^{-}-\mathrm{N}$ can be attributed to incomplete nitrification and partial denitrification. It has been stated by many recent studies that incomplete nitrification in $\mathrm{CWs}$ can lead to the increase of $\mathrm{NO}_{2}^{-}-\mathrm{N}$ concentration in the effluent (Lin et al. 2020).

In addition, the average concentration of total phosphorous (TP) in influent was 2 $\mathrm{mg} / \mathrm{L}$ as depicted in Fig. 2g. For the period, 0-30 days, the TP concentration in SFCW-S1 and SFCW-S3 effluent was low at the beginning. However, TP concentration gradually increased with increase in operating time and the removal efficiency of TP gradually decreased (Fig. 2h). The TP removal efficiency for the SFCW-S4 was the highest, and the effluent TP concentration (except for 5th day) could meet the Class III standard of the EQSSW (GB 3838-2002, China). The XRD peaks data presented in Fig. S3 reflected that the substrate of the four SFCWs primarily consisted of $\mathrm{Si}, \mathrm{Al}, \mathrm{Fe}, \mathrm{S}, \mathrm{Ca}$, and Mg-bearing mineral phases, which indicates that the substrate had the potential for phosphate removal via precipitation and adsorption. The high TP removal efficiency of SFCWs was mainly due to the fact that the chemical precipitation formed by the reaction of metals with 
phosphorus, and the adsorption by the metal oxides and hydroxides in the SFCWs substrate (Torrentó et al. 2010). The reactions were shown as follows (Eqs. (4)-(16)) (Ge et al. 2019, Omwene \&Kobya 2018).

$$
\mathrm{FeS}_{2}+3 \mathrm{NO}_{3}^{-}+2 \mathrm{H}_{2} \mathrm{O} \rightarrow \mathrm{Fe}(\mathrm{OH})_{3}+2 \mathrm{SO}_{4}^{2-}+1.5 \mathrm{~N}_{2}+\mathrm{H}^{+}
$$

\section{Water quality changes along the water flow path}

It was noticed that the effluent $\mathrm{TN}$ concentration gradually decreases along the water flow path of the SFCWs, and correspondingly, the TN removal efficiency gradually increases as shown in Fig. 3a and Fig. 3b. The highest TN removal efficiencies was noticed for SFCW-S2 and SFCW-S4, and the TN concentration for SFCW-S3 wetland was higher, when compared with other SFCWs. The TN removal potential for both SFCW-S2 and SFCW-S4 was much better than that for SFCW-S3 and control wetland SFCW-S1. 
It was detected that $\mathrm{NH}_{4}{ }^{+}-\mathrm{N}$ concentration in the sample was completely removed,

247 when water reaches $15 \mathrm{~cm}$ away from the inlet point; the removal efficiencies found for

248 SFCW-S1, SFCW-S2, SFCW-S3, and SFCW-S4 were 84.47\%, 96.51\%, 96.34\%, and

$24997.66 \%$, respectively (Fig. 3c and Fig. 3d). Because this sampling place was very near to

250 the wetland aeration port, the DO level was higher, which was supportive for the removal

251 of $\mathrm{NH}_{4}{ }^{+}-\mathrm{N}$ by nitrosation reaction. The average effluent $\mathrm{NH}_{4}{ }^{+}-\mathrm{N}$ concentrations for

252 SFCW-S1, SFCW-S2, SFCW-S3, and SFCW-S4 were 1.18, 0.22, 0.27, and $0.26 \mathrm{mg} / \mathrm{L}$,

253 respectively. There was no significant difference for $\mathrm{NH}_{4}{ }^{+}-\mathrm{N}$ removal efficiency among 254 four SFCWs $(p>0.05)$.

255 Furthermore, $\mathrm{NO}_{3}^{-}-\mathrm{N}$ and $\mathrm{NO}_{2}^{-}-\mathrm{N}$ concentrations firstly increased and then 256 decreased along the water flow path of the SFCWs as presented in Fig. 3e and Fig. 3f. In 257 the first zone of the wetland (15 cm away from the water inlet), which is very closest to 258 the aeration port, the higher DO content was found (Fig. S4), which was beneficial for the 259 growth of nitrite and nitrifying bacteria, and existed $\mathrm{NH}_{4}{ }^{+}-\mathrm{N}$ easily oxidized to $\mathrm{NO}_{2}^{-}-\mathrm{N}$ 260 and $\mathrm{NO}_{3}{ }^{-}-\mathrm{N}$. However, with an increase of the water flow path, DO content gradually 261 decreases (Fig. S4), which is conducive to accelerate the conversion of $\mathrm{NO}_{2}^{-}-\mathrm{N}$ and 262 $\mathrm{NO}_{3}{ }^{-}-\mathrm{N}$ to $\mathrm{N}_{2}$.

At the outlet point, $80 \mathrm{~cm}$ away from the water inlet, the concentration of $\mathrm{NO}_{3}{ }^{-}-\mathrm{N}$ accumulated in SFCW-S1 and SFCW-S3 was higher than those determined for SFCW-S2 and SFCW-S4. Because the particle size of pyrite was much smaller than that of ferrous

266 sulfide and ceramsite in the present study, substrate with small particle size could get 267 good contact with microorganisms in wetlands and provide attached biological sites for 268 the growth of microorganisms, thus accelerating the removal of $\mathrm{NO}_{3}{ }^{-}-\mathrm{N}$ by autotrophic 269 denitrifying bacteria (Bosch et al. 2011, Juncher Jørgensen et al. 2009, Torrentó et al. 270 2010). The reason for the low denitrification efficiency of SFCW-S3 might also be that 
271 the particle size of ferrous sulfide was relatively large (Ye et al. 2011), the low solubility

272 of ferrous sulfide decreased its utilization speed duing autotrophic denitrifying process;

273 furthermore, the coverage of biofilm on the ferrous sulfide surface hindered the contact

274 between microorganisms and sulfur-containing substances (Li et al. 2016, Miot et al. 275 2011).

276 The average ratio of $\mathrm{COD}_{\mathrm{Cr}} / \mathrm{NO}_{3}{ }^{-}$along the wetland was $1.82,1.65,2.00$, and 2.41, 277 respectively, which belongs to the low $\mathrm{C} / \mathrm{N}$ ratio wastewater (Anjali \&Sabumon 2015, Xu 278 et al. 2018). No substrate containing sulfur or iron was introduced to SFCW-S1, the 279 carbon sources were insufficient for heterotrophic denitrification, therefore, $\mathrm{NO}_{3}{ }^{-}-\mathrm{N}$ could 280 not be effectively removed in SFCW-S1.

281 The TP concentration gradually decreases with the increasing flow path of the 282 SFCWs, and the removal efficiency gradually increases (Fig. 3g and Fig. 3h). The TP 283 removal efficiency for SFCW-S4 was above 90\%, while the TP removal efficiency of 284 SFCW-S1 was relatively low $(<75 \%)$. The maximal removal efficiency for SFCW-S1, 285 SFCW-S2, SFCW-S3, and SFCW-S4 were 72.64\%, 96.40\%, 81.19\%, and 97.88\%, 286 respectively. In the whole sampling site of the SFCWs (except $15 \mathrm{~cm}$ away from the 287 water inlet), the removal efficiency of TP was in the following order SFCW-S4> 288 SFCW-S2> SFCW-S3> SFCW-S1. There were significant differences found in TP 289 removal efficiency among the four SFCWs $(p<0.05)$, which indicated that the chemical 290 reaction occurred between phosphorus and iron in the substrate, the adsorption of 291 phosphorus by iron oxides and hydroxides in the substrate play an important role in the 292 removal of aqueous phosphorus (Eqs.(4)-(16)).

\section{Analysis for nitrification and denitrification rate}

294 As shown in Fig. 4a, the nitrification rate of SFCW-S1 was the lowest for the 295 aeration zone. The nitrification rate of SFCW-S2, SFCW-S3, and SFCW-S4 was 
significantly different from that of SFCW-S1 $(p<0.01)$, and the nitrification rates of 297 SFCW-S2, SFCW-S3, and SFCW-S4 treatments were 1.37, 1.43, and 1.23 times higher than that of SFCW-S1, respectively. This indicated that the nitrification rates of SFCWs-S2, SFCWs-S3 and SFCWs-S4 containing inorganic electron donor (pyrite or

300 ferrous sulfide) were significantly higher than that of SFCW-S1 without inorganic 301 electron donor. The denitrification rate results for the non-aerated zone of SFCWs 302 exhibited that the denitrification rate of SFCW-S2 and SFCW-S4 was significantly higher than that obtained for SFCW-S1 ( $p<0.05$; Fig. $4 b)$. However, there was no significant difference found between SFCW-S3 and SFCW-S1 $(p>0.05)$. The denitrification rates for SFCW-S2 and SFCW-S4 were 2.31 and 2.22 times greater than calculated for SFCW-S1, 306 respectively, suggesting that SFCW-S2 and SFCW-S4 had higher denitrification 307 efficiency than SFCW-S1.

\section{Analysis for microbial enzyme activity and electron transport system activity}

Ammonia monooxygenase (AMO) is one of the key enzymes found in

310 heterotrophic nitrification process, which assists in $\mathrm{NH}_{4}{ }^{+}-\mathrm{N}$ conversion into $\mathrm{NO}_{3}^{-}-\mathrm{N}$

311 (Zhao et al. 2020). As shown in Fig. 4c, AMO activity in the aeration zone of SFCW-S2, 312 SFCW-S3, and SFCW-S4 were 1.17, 1.21, and 1.26 times higher than the control group 313 SFCW-S1, respectively. There was a significant difference between the AMO activity of 314 SFCW-S2, SFCW-S3, SFCW-S4, and the control group SFCW-S1 AMO activity, 315 respectively $(p<0.05)$, which was similar to the nitrification rate result (Fig. $4 a)$.

316 Denitrifying enzymes are responsible for the bio-reduction of $\mathrm{NO}_{3}^{-}-\mathrm{N}, \mathrm{NO}_{2}^{-}-\mathrm{N}, \mathrm{NO}$ 317 and $\mathrm{N}_{2} \mathrm{O}$ in the denitrification process ( $\mathrm{Wu}$ et al. 2018, Zhao et al. 2020). Nitrate 318 reductase (NAR) activity is critical for the denitrification process, reducing $\mathrm{NO}_{3}{ }^{-}-\mathrm{N}$ to $319 \mathrm{NO}_{2}^{-}-\mathrm{N}$. Fig. 4d shows that the NAR activity for SFCW-S2 and SFCW-S4 was 1.52 and 3202.08 times of that was calculated for SFCW-S1, and 1.41 and 1.93 times of that was 
321 calculated for SFCW-S3, respectively, indicating that the decrease in NAR activity for 322 SFCW-S1 and SFCW-S3 leads to the accumulation of $\mathrm{NO}_{3}{ }^{-} \mathrm{N}$ (Wu et al. 2018). The NIR 323 activity is also considered a key factor for denitrification. Fig. 4e shows that there was no 324 significant difference found in NIR activity among SFCW-S2, SFCW-S3, SFCW-S4 and 325 SFCW-S1 $(p>0.05)$. However, the NIR activity for SFCW-S2 and SFCW-S4 was 326 relatively higher than that obtained for SFCW-S1 and SFCW-S3. For SFCW-S2 and 327 SFCW-S4, denitrification efficiency can be promoted by improving the activities of NAR 328 and NIR, and then catalyzing the reduction of $\mathrm{NO}_{3}^{-}-\mathrm{N}$ and $\mathrm{NO}_{2}^{-}-\mathrm{N}$, which is considered to 329 be the reason for the increased $\mathrm{TN}$ removal efficiency and the decreased $\mathrm{NO}_{3}^{-}-\mathrm{N}$ 330 accumulation (Fig. 2b and Fig. 2e).

331 The efficiency for nitrification and denitrification process mainly depends on the 332 efficient transport of electrons, that can be assessed using ETSA (Wan et al. 2016, Wu et 333 al. 2018). AMO, NAR, and NIR obtained electrons from electron transport system, and 334 the activities of these enzymes are directly related to nitrogen removal efficiency. The 335 AMO, NAR, and NIR activity obtained for SFCW-S1 was comparatively low (Fig. 4c, 336 Fig. 4d and Fig. 4e), which was an important reason for the low ETSA (Fig. 4f).

337 Analysis for microbial community structure

338 The structure and composition of microbial community in SFCWs at the phylum 339 level has shown in Fig. 5a. The dominant bacterial community has divided into 13 phyla, 340 Proteobacteria accounts for the highest relative abundance at each sampling point, 341 ranging from $44.60 \%$ to $87.16 \%$. Proteobacteria is usually the largest phyla found in 342 constructed wetland systems (Guan et al. 2015, Ibekwe et al. 2016). Proteobacteria 343 contain bacteria responsible for nitrification and denitrification activities and various 344 metabolic bacteria, which play a vital role in the removal of organic matter, nitrogen, and 345 phosphorus. 
Cyanobacteria are often detected in high nutrient wastewater as an indicator

347 bacterium (Adyasari et al. 2019), which was enriched in SFCW-S1 and SFCW-S4.

348 Cyanobacteria with high relative abundance detected in SFCW-S1 indicated that the TN

349 removal performance for SFCW-S1 was lower than that observed for the other SFCWs.

350 Relative higher abundance of Cyanobacteria noticed for SFCW-S4 might be assigned to

351 the accumulation of phosphorus in SFCW-S4 substrate and biofilm. Moreover,

352 Planctomycetes contain bacteria related to Anammox (Bae et al. 2010). Planctomycetes

353 not only has the function of Anammox, but also may play denitrification function (Du et

354 al. 2020, Ishimoto et al. 2020, Kumar et al. 2020, Park et al. 2020, Vipindas et al. 2020).

355 It was found that the proportion of Bacteroidetes has increased with the outbreak of

356 cyanobacterial blooms and gradually became the dominant bacteria found in eutrophic

357 water (Kolmonen et al. 2004, Rashidan \&Bird 2001, Wu et al. 2007). No matter in an

358 aerated zone or non-aerated zone, the relative abundance of Bacteroidetes in SFCW-S1

359 was much higher than that monitored for SFCW-S2, SFCW-S3, and SFCW-S4,

360 respectively, indicating the poor performance of denitrification and phosphorus removal

361 for SFCW-S1.

362 Fig. $5 b$ shows the microbial community structure composition of the overall four

363 SFCWs at the genus level. Acinetobacter commonly exists around the roots of CWs, and

364 most of them are aerobic bacteria, which can metabolize by using ammonia, nitrogen and

365 glucose. This is consistent with the fact that the proportion of Acinetobacter in the

366 aeration zones of the overall four SFCWs was higher than that in the non-aerated zones.

367 Rhodobacter is a kind of phototrophic bacteria related to Fe (II) oxidation and nitrogen

368 removal (Chakraborty \&Picardal 2013). Higher abundance of Rhodobacter detected in

369 SFCWs containing iron compared with control SFCW-1 suggested that the addition of 
pyrite and ferrous sulfide changed microbial community structure and then improved denitrification efficiency.

Thiobacillus has the potential to use the sulfur present in pyrite for autotrophic denitrification, and the proportions of Thiobacillus found in SFCW-S1, SFCW-S2, SFCW-S3, and SFCW-S4 were $0.26 \%, 13.00 \%, 0.20 \%$, and $1.90 \%$, respectively. This trend indicates that Thiobacillus played an important role for the autotrophic denitrification of SFCW-S2 and SFCW-S4.

Pseudomonas is a genus of denitrifying bacteria, which is the dominant group of nitrifying bacteria in CWs and plays an important role in heterotrophic denitrification (Nicomrat et al. 2006, Okada et al. 2005, Rìos-Montes et al. 2017). Pseudomonas contributes to removing both $\mathrm{COD}_{\mathrm{Cr}}$ and $\mathrm{TN}$, and may also be the dominant genus for $\mathrm{TP}$ removal (Ge et al. 2019). The relative abundance of Pseudomonas for SFCW-S1, SFCW-S2, SFCW-S3, and SFCW-S4 were 7.61\%, 0.84\%, 0.27\%, and $1.99 \%$, respectively, suggesting that Pseudomonas played an important role in wetland nitrogen and phosphorus removal for SFCW-S1.

Aerobic denitrifying microorganisms such as Paracoccus, Pseudomonas, Rhizobium, Novosphingobium, and Sphingomonas were detected in aerated zones of the overall four SFCWs. Bacterial denitrification is not strictly an anaerobic process, denitrification may also exist under aerobic conditions. Aerobic denitrifying microorganisms have potential for nitrification and denitrification process simultaneously. Geobacters are iron-reducing bacteria with organic matter as an electron donor (Ge et al. 2019, Leang et al. 2003), which contribute to the removal of $\mathrm{COD}_{\mathrm{Cr}}$. In both aerated and non-aerated zones, the proportion of geobacters in SFCW-S2, SFCW-S3, and SFCW-S4 was higher than that found in SFCW-S1, indicating that iron-reducing process was more dominant for SFCW-S2, SFCW-S3, and SFCW-S4 than for SFCW-S1. 
It has been reported that Paracoccus is more suitable to live in the water

environment having higher TN content (Pan et al. 2020, Zhang et al. 2020). The proportion of Paracoccus detected for SFCW-S1, SFCW-S2, SFCW-S3, and SFCW-S4 were $0.31 \%, 0.05 \%, 0.98 \%$, and $0.16 \%$, respectively (Fig. 5b). For SFCW-S3 and

SFCW-S1, the proportion was relatively higher, while SFCW-S2 and SFCW-S4 were 400 relatively low, indicating that the TN content for SFCW-S3 and SFCW-S1 were relatively 401 higher, which was in-consistent with the results presented in Fig. 2a.

\section{Canonical correspondence analysis}

Canonical correspondence analysis (CCA) is a nonlinear multivariate direct gradient analysis method, which is commonly used to study the correlation between microbial community structure and water environmental factors (Ter Braak \&Prentice 1988). Fig. 6 demonstrated the relationship among the microbial community at the phylum level and seven environmental factors. The correlation coefficient between the first and second axes of environmental factors was 0 , which indicates that the analysis results are reliable. The 409 principal components (AX1 and AX2) can explain $79.11 \%$ of the bacterial structure, with 410 AX1 explaining up to $63.01 \%$ and $\mathrm{AX} 2$ up to $16.1 \%$ of the total variation. Among the 411 environmental factors analyzed, water temperature $\mathrm{T}$ and $\mathrm{NH}_{4}{ }^{+}-\mathrm{N}$ were positively 412 correlated with the first ordering axis $(\mathrm{AX} 1)$, while $\mathrm{TP}, \mathrm{COD}_{\mathrm{Cr}}, \mathrm{TN}, \mathrm{NO}_{2}^{-}-\mathrm{N}$, and $\mathrm{NO}_{3}^{-}-\mathrm{N}$ 413 were negatively correlated with the AX1.

414 Furthermore, temperature $\mathrm{T}, \mathrm{NH}_{4}{ }^{+}-\mathrm{N}$, and $\mathrm{TP}$ were positively correlated with the 415 second sorting axis $(\mathrm{AX} 2)$, while $\mathrm{COD}_{\mathrm{Cr}}, \mathrm{TN}, \mathrm{NO}_{2}^{-}-\mathrm{N}$, and $\mathrm{NO}_{3}{ }^{-}-\mathrm{N}$ were negatively 416 correlated the AX2. Proteobacteria was positively correlated with $\mathrm{TP}, \mathrm{COD}_{\mathrm{Cr}}, \mathrm{TN}$, $417 \mathrm{NO}_{2}^{-}-\mathrm{N}$, and $\mathrm{NO}_{3}{ }^{-}-\mathrm{N}$, and negatively correlated with $\mathrm{NH}_{4}{ }^{+}-\mathrm{N}$ and water temperature T. In 418 addition, Bacteroidetes, Planctomycetes, Acidobacteria, and Actinobacteria were 419 positively correlated with water temperature $\mathrm{T}$ and $\mathrm{NH}_{4}{ }^{+}-\mathrm{N}$ and negatively correlated with 
$421 \mathrm{AX} 2$, it can be noticed that $\mathrm{NO}_{2}^{-}-\mathrm{N}, \mathrm{TP}$, and water temperature $\mathrm{T}$ can significantly affect

422 the microbial community at the phylum level.

\section{Conclusion}

424 The concentration of $\mathrm{NH}_{4}{ }^{+}-\mathrm{N}$ in effluent drops rapidly after intermittent aeration in 425 the front section of the SFCWs, and the removal efficiency of $\mathrm{NH}_{4}{ }^{+}-\mathrm{N}$ gradually reaches over $90 \%$. The removal efficiency for SFCW-S2 and SFCW-S4 exhibited better removal performance of TN and TP than wetland SFCW-S3 and wetland SFCW-S1. The average effluent TP concentration for wetland SFCW-S4 could meet the Class III standard of EQSSW (GB 3838-2002, China, and the phosphorus removal efficiency was the highest.

430 Nitrification rate and AMO activity in aeration zone of overall four SFCWs were not 431 significantly different. The denitrification rates, NAR, NIR, and ETSA of SFCW-S2 and SFCW-S4 were higher than those of SFCW-S1 and SFCW-S3 in the non-aerated zone. Proteobacteria accounts for the highest relative abundance found at each sampling point, 434 ranging from $44.60 \%$ to $87.16 \%$. Heterotrophic denitrification was the main process in 435 wetland SFCW-S1, Thiobacillus plays an important role in pyrite-driven autotrophic denitrification process of wetland SFCW-S2 and SFCW-S4. $\mathrm{NO}_{2}{ }^{-}-\mathrm{N}, \mathrm{TP}$, and water temperature T can significantly affect the microbial community at the phylum level.

\section{Declarations:}

440 Ethics approval and consent to participate: Not applicable.

441 Consent for publication: Not applicable.

442 Availability of data and materials: The datasets used and/or analyzed during the current 443 study are available from the corresponding author on reasonable request. 
444 Competing interests: The authors declare that they have no competing interests.

445 Funding: This work was supported by the National Water Pollution Control and 446 Treatment Science and Technology Major Project (2017ZX07603-004), the Open Project 447 of State Key Laboratory of Pollution Control and Resource Reuse (PCRRF19034), and 448 the National Natural Science Foundation of China (51208163).

449 Authors' contributions: Liya Li: Writing-original draft, Data curation, Validation, 450 Visualization. Jingwei Feng: Writing-Review and Editing, Visualization. Liu Zhang: 451 Conceptualization, Supervision. Hao Yin: Resources, Project administration. Chunli Fan: 452 Data curation, Validation. Zechun Wang: Data curation, Validation. Menglei Zhao: 453 Data curation, Validation. Chengchang Ge: Data curation, Validation. Hao Song: Data 454 curation, Validation.

455 Acknowledgements: We are grateful for the financial support from the National Water 456 Pollution Control and Treatment Science and Technology Major Project 457 (2017ZX07603-004), the Open Project of State Key Laboratory of Pollution Control and 458 Resource Reuse (PCRRF19034), and the National Natural Science Foundation of China 459 (51208163).

460

$461 \quad$ References

462 Abou-Kandil A, Shibli A, Azaizeh H, Wolff D, Wick A, Jadoun J (2021) Fate and 463 removal of bacteria and antibiotic resistance genes in horizontal subsurface 
Adyasari D, Hassenrück C, Oehler T, Sabdaningsih A, Moosdorf N (2019) Microbial community structure associated with submarine groundwater discharge in northern Java (Indonesia)

Sci.

Total

Environ.

689:

$590-601$. https://doi.org/10.1016/j.scitotenv.2019.06.193

Anjali G, Sabumon PC (2015) Development of enhanced SNAD process in a down-flow packed bed reactor for removal of higher concentrations of $\mathrm{NH}_{4}-\mathrm{N}$ and COD. J.

\section{Enviro. Chem. Eng. 3: 1009-1017. https://doi.org/10.1016/j.jece.2015.02.022}

Bae H, Chung YC, Jung JY (2010) Microbial community structure and occurrence of diverse autotrophic ammonium oxidizing microorganisms in the anammox process. Water Sci. Technol. 61: 2723-2732. https://doi.org/10.2166/wst.2010.075

Baldovi AA, de Barros Aguiar AR, Benassi RF, Vymazal J, de Jesus TA (2021) Phosphorus removal in a pilot scale free water surface constructed wetland: concentration.

Bioresour.

Technol.

102:

4913-4916. https://doi.org/10.1016/j.biortech.2010.12.116 
Bosch J, Lee KY, Jordan G, Kim KW, Meckenstock RU (2011) Anaerobic, nitrate-dependent oxidation of pyrite nanoparticles by thiobacillus denitrificans. Environ. Sci. Technol. 46: 2095-2101. https://doi.org/10.1021/es2022329

Buelna G, Dubé R, Turgeon N (2008) Pig manure treatment by organic bed biofiltration. Desalination 231: 297-304. https://doi.org/10.1016/j.desal.2007.11.049

Chakraborty A, Picardal F (2013) Induction of nitrate-dependent Fe(II) oxidation by Fe(II) in Dechloromonas sp. strain UWNR4 and Acidovorax sp. strain 2AN. Appl. Environ. Microbiol. 79: 748-752. https://doi.org/10.1128/AEM.02709-12

Chiu YC, Chung MS (2003) Determination of optimal COD/nitrate ratio for biological denitrification. Int. Biodeterior. Biodegrad. 51: 43-49. https://doi.org/10.1016/S0964-8305(02)00074-4

Dong X, Reddy GB (2012) Ammonia-oxidizing bacterial community and nitrification rates in constructed wetlands treating swine wastewater. Ecol. Eng. 40: 189-197. https://doi.org/10.1016/j.ecoleng.2011.12.022

Du S, Tao Y, Zhang M, Zhu M, Wang X (2020) Distinct microbial communities and their networks in an anammox coupled with sulfur autotrophic/mixotrophic denitrification system. Environ. Pollut. 262: 114190. https://doi.org/10.1016/j.envpol.2020.114190

Ge Z, Wei D, Zhang J, Hu J, Liu Z, Li R (2019) Natural pyrite to enhance simultaneous long-term nitrogen and phosphorus removal in constructed wetland: Three years of pilot study. Water Res. 148: 153-161. https://doi.org/10.1016/j.watres.2018.10.037 
504 Guan W, Yin M, He T, Xie S (2015) Influence of substrate type on microbial community 505 structure in vertical-flow constructed wetland treating polluted river water. Environ. 506 Sci. Pollut. Res. 22: 16202-16209. https://doi.org/10.1007/s11356-015-5160-9

507 Ibekwe AM, Ma J, Murinda S, Reddy GB (2016) Bacterial community dynamics in 508 surface flow constructed wetlands for the treatment of swine waste. Sci. Total $509 \quad$ Environ. 544: 68-76. https://doi.org/10.1016/j.scitotenv.2015.11.139

510 Ishimoto C, Sugiyama T, Matsumoto T, Uenishi H, Waki M (2020) Full-scale 511 simultaneous partial nitrification, anammox, and denitrification process for treating 512 https://doi.org/10.2166/wst.2020.120

514 Juncher Jørgensen C, Jacobsen OS, Elberling B, Aamand J (2009) Microbial oxidation of Technol. 43: 4851-4857. https://doi.org/10.1021/es803417s

517 Kolmonen E, Sivonen K, Rapala J, Haukka K (2004) Diversity of cyanobacteria and 518 heterotrophic bacteria in cyanobacterial blooms in Lake Joutikas, Finland. Aquat. 519 Microb. Ecol. 36: 201-211. https://doi.org/10.3354/ame036201

520 Kumar G, Radha V, Jagadeeshwari U, Sasikala C, Venkata Ramana C (2020) Bacterial 521 communities of sponges from the wetland ecosystem of Little Rann of Kutch, India 522 with particular reference to Planctomycetes. 3 Biotech 10: 478. $523 \quad$ https://doi.org/10.1007/s13205-020-02449-1 
524 Leang C, Coppi MV, Lovley DR (2003) OmcB, a c-type polyheme cytochrome, involved

525 in Fe(III) reduction in Geobacter sulfurreducens. J. Bacteriol. 185: 2096-2103.

$526 \quad$ https://doi.org/10.1128/jb.185.7.2096-2103.2003.

527 Li H, Chi Z, Yan B, Cheng L, Li J (2017) An innovative wood-chip-framework substrate

528 used as slow-release carbon source to treat high-strength nitrogen wastewater. J.

$529 \quad$ Environ. Sci. 51: 275-283. https://doi.org/10.1016/j.jes.2016.07.008

530 Li R, Morrison L, Collins G, Li A, Zhan X (2016) Simultaneous nitrate and phosphate

531 removal from wastewater lacking organic matter through microbial oxidation of

532 pyrrhotite coupled to nitrate reduction. Water Res. 96: 32-41. https://doi.org/10.1016/j.watres.2016.03.034

534 Li R, Wei D, Wang W, Zhang Y (2020) Pyrrhotite-sulfur autotrophic denitrification for 535 https://doi.org/10.1016/j.biortech.2020.123302

538 Lin Z, Xu F, Wang Y, Huang W, Zhou J, He Q, Zhou J (2020) Autotrophic nitrogen removal by partial nitrification-anammox process in two-stage sequencing batch constructed wetlands for low-strength ammonium wastewater. J. Water Process Eng. 38: 101625. https://doi.org/10.1016/j.jwpe.2020.101625

542 Miot J, Maclellan K, Benzerara K, Boisset N (2011) Preservation of protein globules and 543 peptidoglycan in the mineralized cell wall of nitrate-reducing, iron(II)-oxidizing 
544 bacteria: A cryo-electron microscopy study. Geobiol. 9: 459-470. $545 \quad$ https://doi.org/10.1111/j.1472-4669.2011.00298.x

546 Nicomrat D, Dick WA, Tuovinen OH (2006) Assessment of the microbial community in 547 a constructed wetland that receives acid coal mine drainage. Microb. Ecol. 51: 83-89. $548 \quad$ https://doi.org/10.1007/s00248-005-0267-z

549 Okada N, Nomura N, Nakajima-Kambe T, Uchiyama H (2005) Characterization of the 550 aerobic denitrification in Mesorhizobium sp. strain NH-14 in comparison with that in 551 related rhizobia. Microbes Enviro.20: 208-215. https://doi.org/10.1264/jsme2.20.208

552 Omwene PI, Kobya M (2018) Treatment of domestic wastewater phosphate by 553 electrocoagulation using $\mathrm{Fe}$ and $\mathrm{Al}$ electrodes: A comparative study. Process Saf. $554 \quad$ Environ. Prot. 116: 34-51. https://doi.org/10.1016/j.psep.2018.01.005

555 Pan Z, Zhou J, Lin Z, Wang Y, Zhao P, Zhou J, Liu S, He X (2020) Effects of COD/TN 556 ratio on nitrogen removal efficiency, microbial community for high saline 557 wastewater treatment based on heterotrophic nitrification-aerobic denitrification

560 Park M, Kim J, Lee T, Oh YK, Cho S (2020) Correlation of microbial community with 561 salinity and nitrogen removal in an anammox-based denitrification system. 562 Chemosphere 263: 128340. https://doi.org/10.1016/j.chemosphere.2020.128340 
563 Rashidan KK, Bird DF (2001) Role of predatory bacteria in the termination of a

bloom. Microb.

Ecol.

41:

97-105. https://doi.org/10.1007/s002480000074

Rìos-Montes KA, Casas-Zapata JC, Briones-Gallardo R, Peñuela G (2017) Optimal conditions for chlorothalonil and dissolved organic carbon in horizontal subsurface flow constructed wetlands. J. Environ. Sci. Heal. Part B 52: 274-281. https://doi.org/10.1080/03601234.2016.1273005

Rizzo A, Tondera K, Pálfy TG, Dittmer U, Meyer D, Schreiber C, Zacharias N, Ruppelt JP, Esser D, Molle P, Troesch S, Masi F (2020) Constructed wetlands for combined sewer overflow treatment: A state-of-the-art review. Sci. Total Environ. 727: 138618. https://doi.org/10.1016/j.scitotenv.2020.138618

Sahinkaya E, Dursun N, Kilic A, Demirel S, Uyanik S, Cinar O (2011) Simultaneous heterotrophic and sulfur-oxidizing autotrophic denitrification process for drinking water treatment: Control of sulfate production. Water Res. 45: 6661-6667. https://doi.org/10.1016/j.watres.2011.09.056

Si Z, Song X, Wang Y, Cao X, Zhao Y, Wang B, Chen Y, Arefe A (2018) Intensified heterotrophic denitrification in constructed wetlands using four solid carbon sources: Denitrification efficiency and bacterial community structure. Bioresour. Technol. 267: 416-425. https://doi.org/10.1016/j.biortech.2018.07.029

Sun G, Gray KR, Biddlestone AJ, Allen SJ, Cooper DJ (2004) Effect of effluent recirculation on the performance of a reed bed system treating agricultural 

nitrogen removal by heterotrophic nitrification aerobic denitrification bacteria in two pilot-scale tidal flow constructed wetlands: Influence of influent $\mathrm{C} / \mathrm{N}$ ratios and tidal strategies.

Bioresour.

Technol.

302:

122803. https://doi.org/10.1016/j.biortech.2020.122803

591 Ter Braak CJF, Prentice IC (1988) A theory of gradient analysis. Adv. Ecol. Res. 18: 271-317. https://doi.org/10.1016/S0065-2504(08)60183-X

593 Torrentó C, Cama J, Urmeneta J, Otero N, Soler A (2010) Denitrification of groundwater

594 with pyrite and Thiobacillus denitrificans. Chem. Geol. 278: 80-91. $595 \quad$ https://doi.org/10.1016/j.chemgeo.2010.09.003

596 Vipindas PV, Krishnan KP, Rehitha TV, Jabir T, Dinesh SL (2020) Diversity of sediment 597 associated Planctomycetes and its related phyla with special reference to anammox 598 bacterial community in a high Arctic fjord. World J. Microbiol. Biotechnol. 36: 107. $599 \quad$ https://doi.org/10.1007/s11274-020-02886-3

600 Wan R, Chen Y, Zheng X, Su Y, Li M (2016) Effect of $\mathrm{CO}_{2}$ on microbial denitrification 601 via inhibiting electron transport and consumption. Environ. Sci. Technol. 50: 602 9915-9922. https://doi.org/10.1021/acs.est.5b05850 
603 Wang JJ, Huang BC, Li J, Jin RC (2020) Advances and challenges of sulfur-driven

604 autotrophic denitrification (SDAD) for nitrogen removal. Chin. Chem. Lett. 31:

605 2567-2574. https://doi.org/10.1016/j.cclet.2020.07.036

606 Wang SS, Cheng HY, Zhang H, Su SG, Sun YL, Wang HC, Han JL, Wang AJ (2021)

607 Sulfur autotrophic denitrification filter and heterotrophic denitrification filter:

608 Comparison on denitrification performance, hydrodynamic characteristics and

609 operating cost. Environ. Res.: 111029. https://doi.org/10.1016/j.envres.2021.111029

610 Wu X, Xi W, Ye W, Yang H (2007) Bacterial community composition of a shallow

611 hypertrophic freshwater lake in China, revealed by 16S rRNA gene sequences.

612 FEMS Microbiol. Ecol. 61: 85-96. https://doi.org/10.1111/j.1574-6941.2007.00326.x

613 Wu Z, Xu F, Yang C, Su X, Guo F, Xu Q, Peng G, He Q, Chen Y (2018) Highly efficient

614 nitrate removal in a heterotrophic denitrification system amended with redox-active

615 biochar: A molecular and electrochemical mechanism. Bioresour. Technol. 275:

616 297-306. https://doi.org/10.1016/j.biortech.2018.12.058

617 Xu Z, Dai X, Chai X (2018) Effect of different carbon sources on denitrification

618 performance, microbial community structure and denitrification genes. Sci. Total

619 Environ. 634: 195-204. https://doi.org/10.1016/j.scitotenv.2018.03.348

620 Yang X, He Q, Guo F, Sun X, Zhang J, Chen M, Vymazal J, Chen Y (2020) Nanoplastics

621 disturb nitrogen removal in constructed wetlands: Responses of microbes and

622 macrophytes. Environ. Sci. Technol. 54: 14007-14016.

$623 \quad$ https://doi.org/10.1021/acs.est.0c03324 
624 Ye L, Shao MF, Zhang T, Tong AHY, Lok S (2011) Analysis of the bacterial community 625 in a laboratory-scale nitrification reactor and a wastewater treatment plant by 454-pyrosequencing. Water Res.

45:

4390-4398. https://doi.org/10.1016/j.watres.2011.05.028

Yuan C, Zhao F, Zhao X, Zhao Y (2020) Woodchips as sustained-release carbon source to enhance the nitrogen transformation of low $\mathrm{C} / \mathrm{N}$ wastewater in a baffle subsurface flow constructed wetland. Chem. Eng. J. 392: 124840. https://doi.org/10.1016/j.cej.2020.124840

632 Zhang Q, Chen X, Zhang Z, Luo W, Wu H, Zhang L, Zhang X, Zhao T (2020)

633 Performance and microbial ecology of a novel moving bed biofilm reactor process 634 inoculated with heterotrophic nitrification-aerobic denitrification bacteria for high 635 ammonia nitrogen wastewater treatment. Bioresour. Technol. 315: 123813. $636 \quad$ https://doi.org/10.1016/j.biortech.2020.123813

637 Zhang X, Song Z, Guo W, Lu Y, Qi L, Wen H, Ngo HH (2017) Behavior of nitrogen 638 removal in an aerobic sponge based moving bed biofilm reactor. Bioresour. Technol. 245: 1282-1285. https://doi.org/10.1016/j.biortech.2017.08.106

640 Zhao S, Su X, Wang Y, Yang X, Bi M, He Q, Chen Y (2020) Copper oxide nanoparticles 641 inhibited denitrifying enzymes and electron transport system activities to influence 642 soil denitrification and $\mathrm{N}_{2} \mathrm{O}$ emission. Chemosphere 245: 125394. $643 \quad$ https://doi.org/10.1016/j.chemosphere.2019.125394 


\section{Figures}

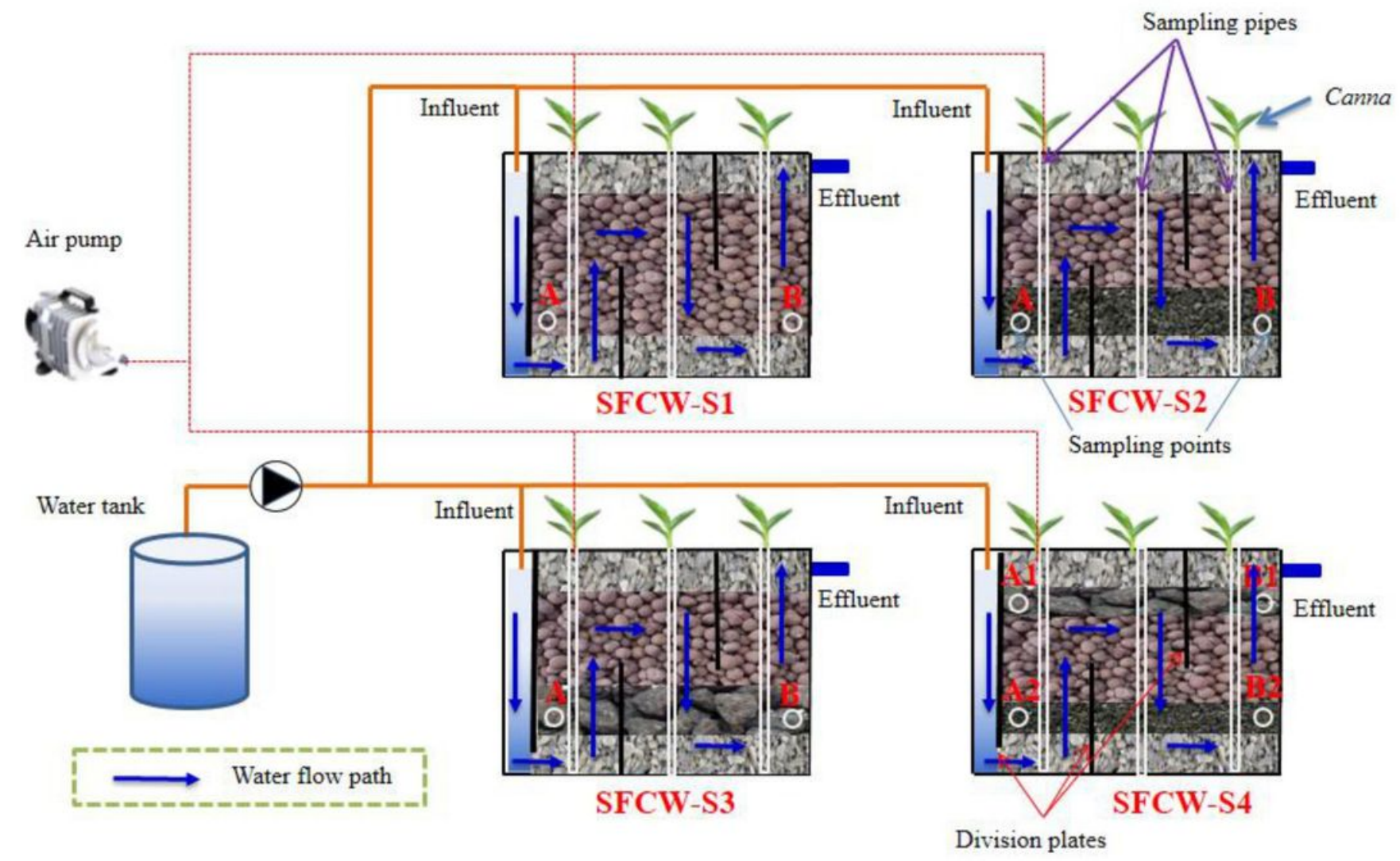

Fig. 1

\section{Figure 1}

Experimental apparatus diagram of subsurface flow constructed wetlands ( $A$ and $B$ refer to the sampling points for microbial community determination; Sample A and B in SFCW-S4 are the mixture of A1+A2, and B2+B2, respectively) 

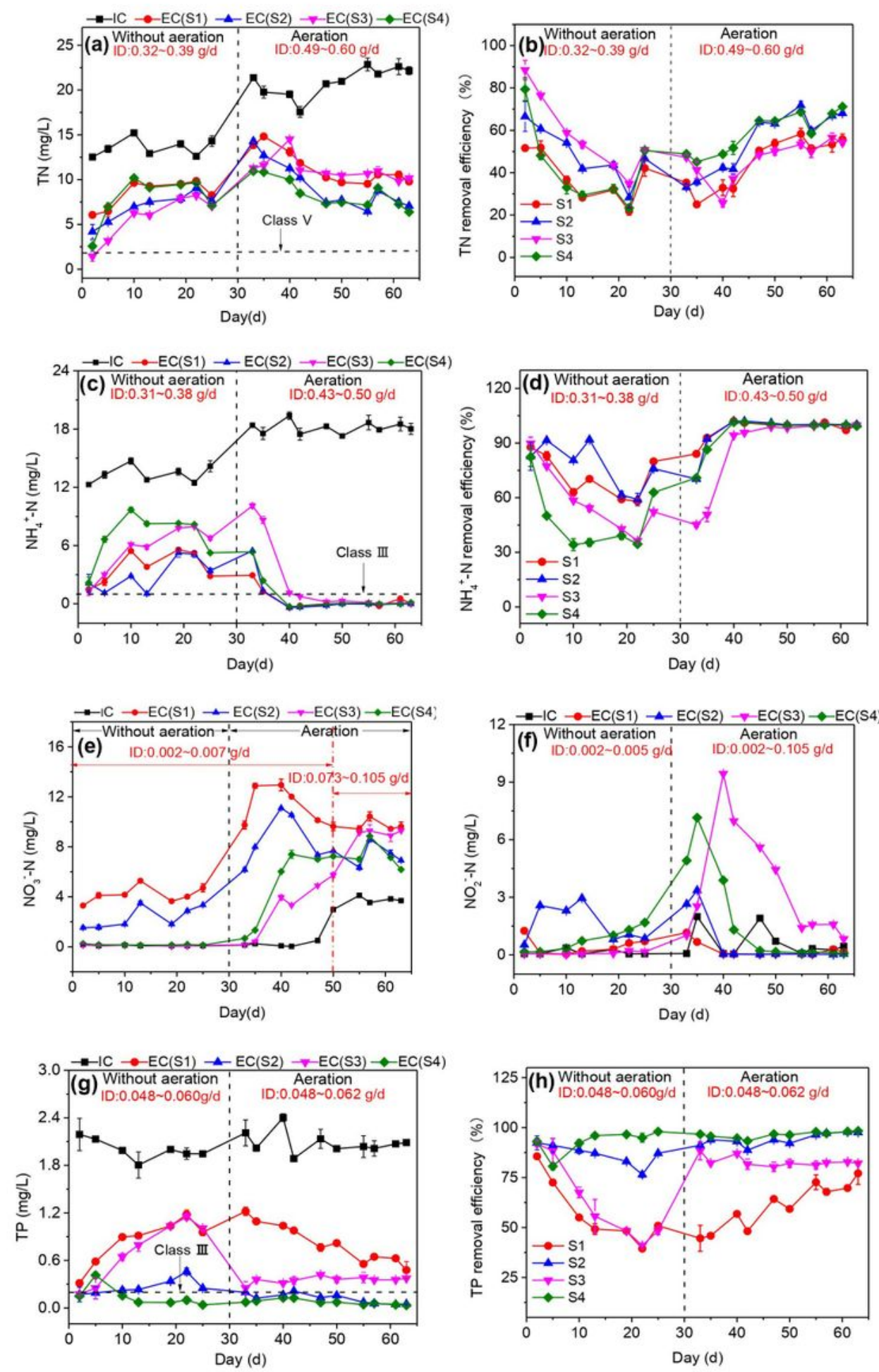

Figure 2

Removal of TN $(a, b), N H 4+-N(c, d)$, NO3-N (e), NO2--N (f), TP $(g, h)$ by SFCWs filled with different substrates (HRT = 2d; IC refers to influent concentration; ID refers to influent loading; EC refers to effluent concentration; SFCW-S1, SFCW-S2, SFCW-S3, and SFCW-S4 refer to SFCWs with different substrates: ceramsite (S1), ceramsite+pyrite (S2), ceramsite+ferrous sulfide (S3) and ceramsite+pyrite+ferrous 
sulfide (S4); "Class III" and "Class V" refer to the Class III and Class V standard of the Environmental Quality Standard for Surface Water (GB 3838-2002, China))
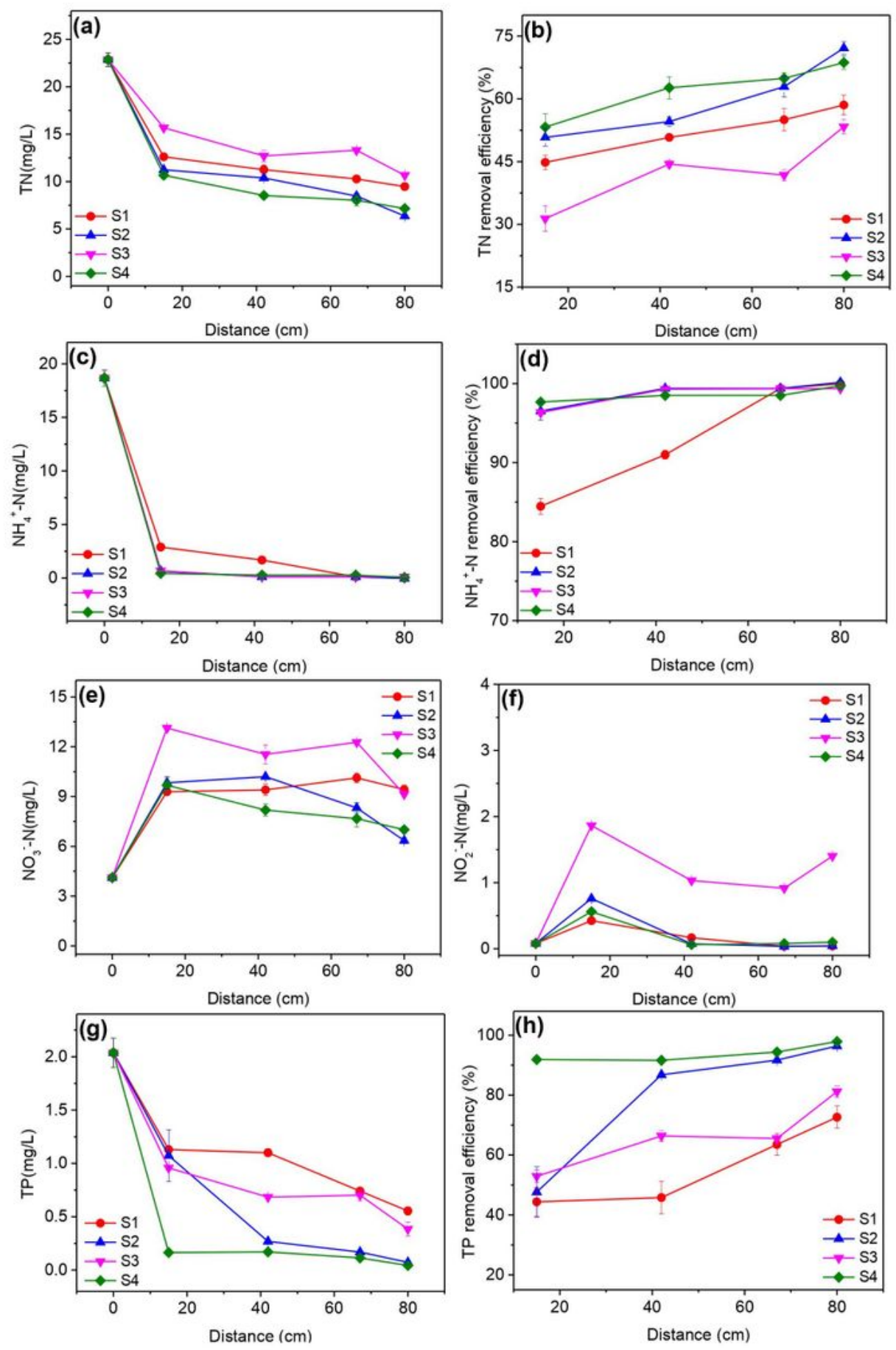

Fig. 3

\section{Figure 3}

Variations in TN $(a, b), N H 4+-N(c, d), N O 3--N(e), N O 2-N(f), T P(g, h)$ along the water flow path 

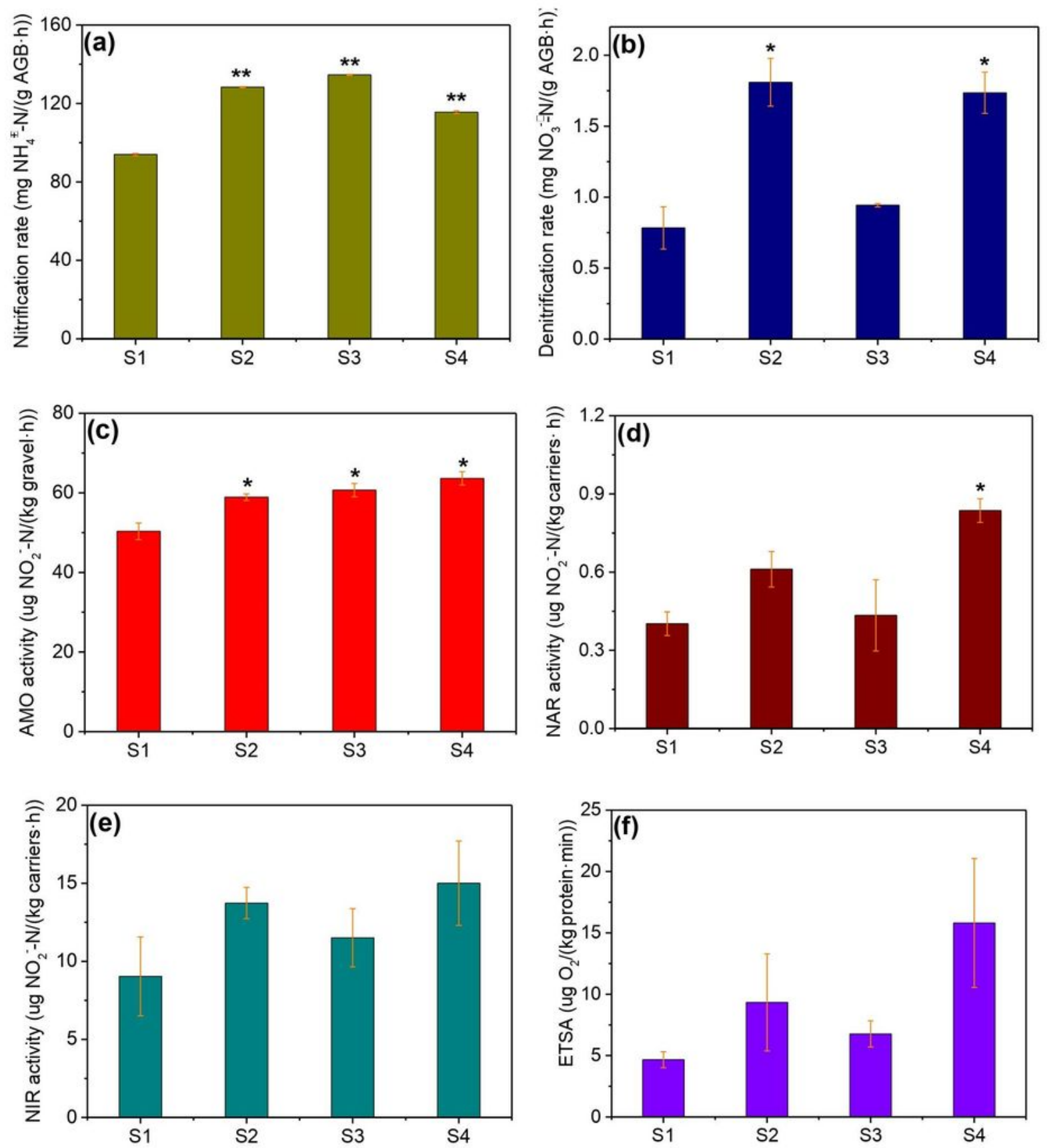

Fig. 4

\section{Figure 4}

Nitrification rate in aeration zone (a), denitrification rate in non-aeration zone (b), AMO activity in aeration zone (c), NAR (d), NIR activities (e) and ETSA (f) in non-aeration zone of the SFCWs (* indicates significant difference between the experimental group (S2, S3 and S4) and the control group (S1), oneway ANOVA, ${ }^{*} p<0.05,{ }^{\star *} p<0.01$ ) 

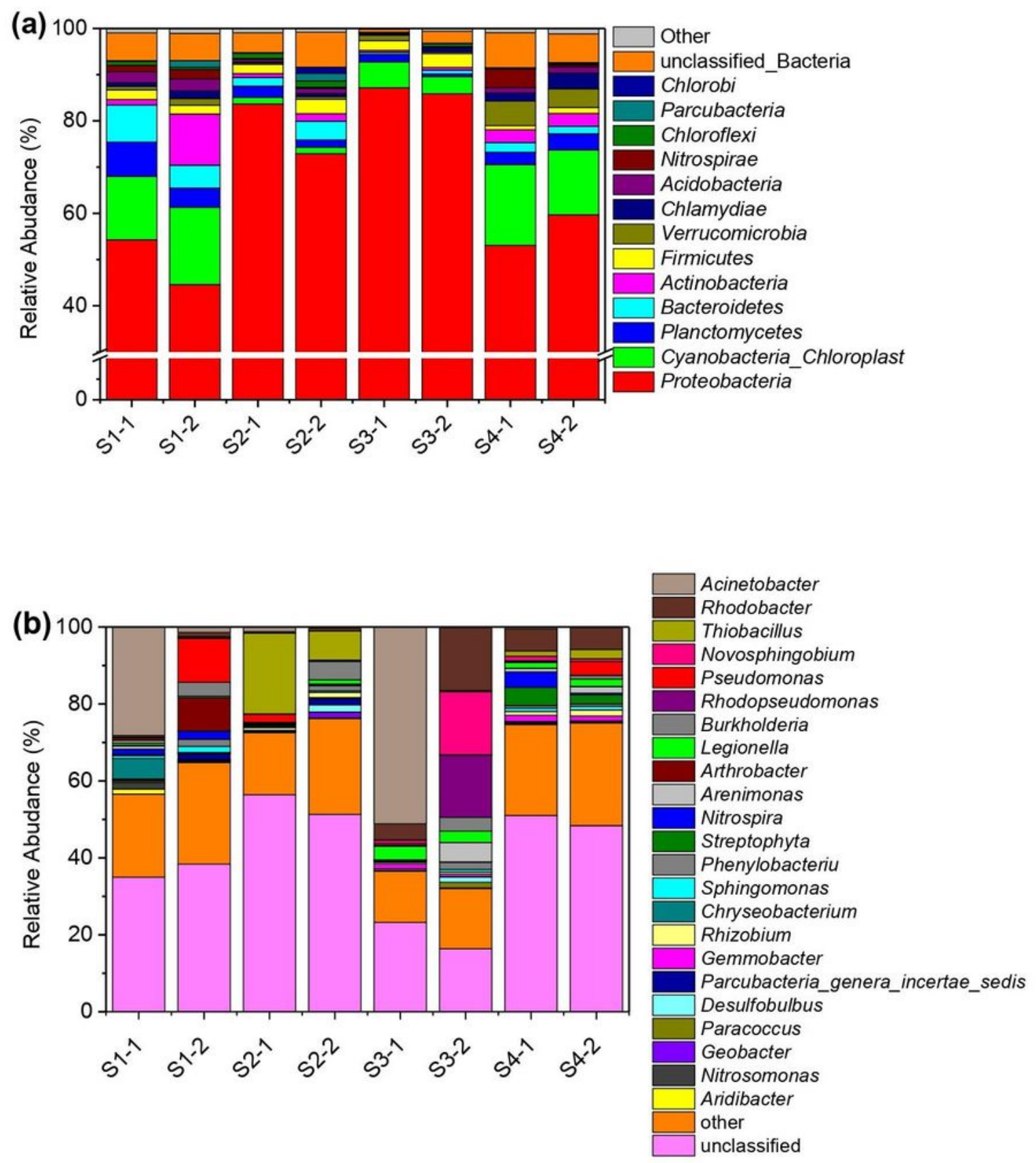

Fig. 5

\section{Figure 5}

Microbial community composition of biofilm samples at the phylum level (a) and genus level (b) (S1-1, S2-1, S3-1, and S4-1 refer to sample in the aerated zone of the SFCW-S1, SFCW-S2, SFCW-S3, and SFCWS4, respectively; S1-2, S2-2, S3-2, and S4-2 refer to sample in the non-aerated zone of the SFCW-S1, SFCW-S2, SFCW-S3, and SFCW-S4, respectively) 


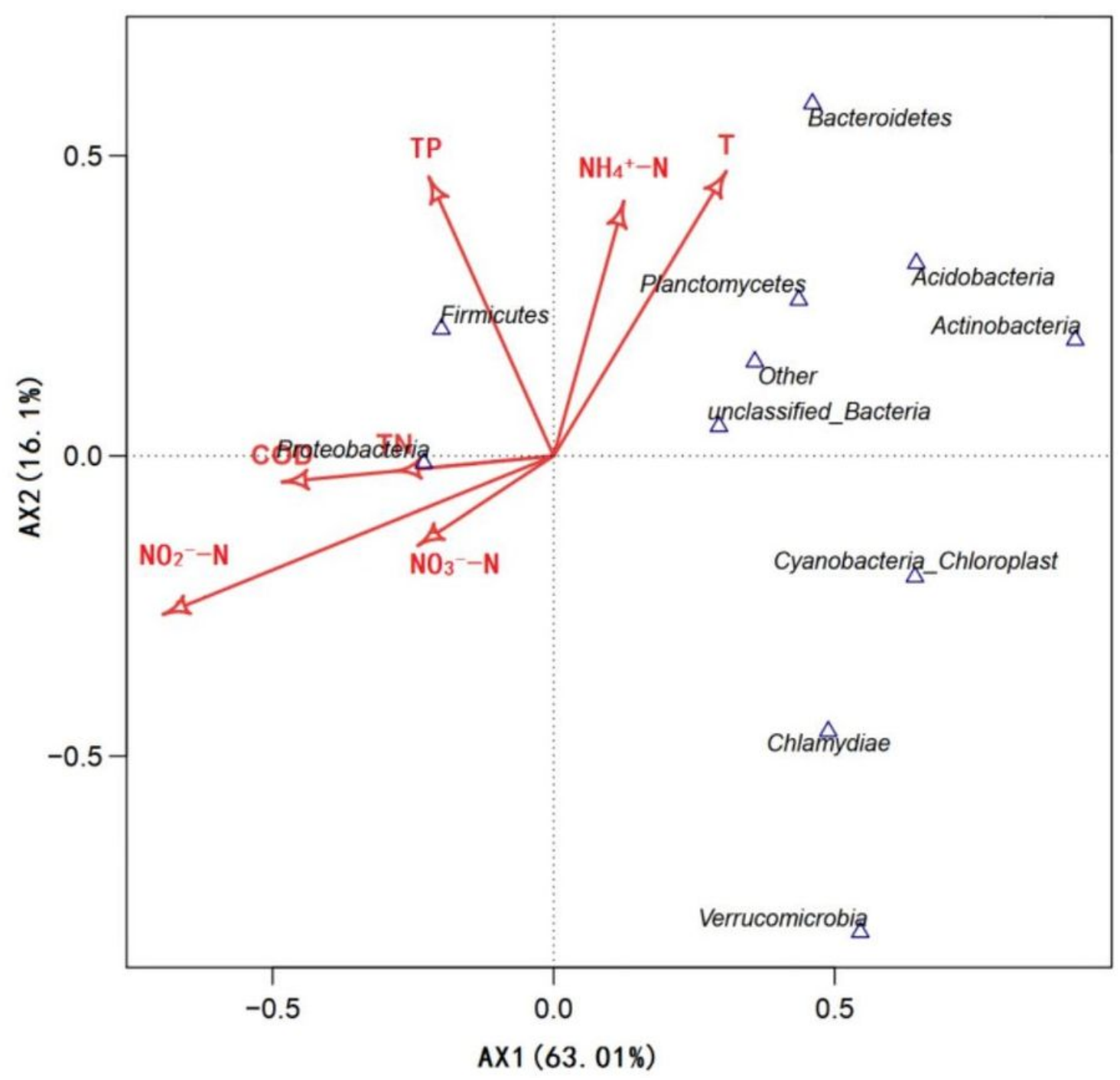

Fig. 6

Figure 6

CCA sequencing of environmental factors and constructed wetlands bacteria at the phylum level

\section{Supplementary Files}

This is a list of supplementary files associated with this preprint. Click to download. 
- 2020.04.05LiyaLiSupplementaryinformation.docx 